\title{
Developing teachers, developing as a teacher: A story about a story
}

\author{
Kate Bennie \\ University of Cape Town \\ Email: kbennie@maths.uct.ac.za
}

\begin{abstract}
In this paper I reflect on my changing roles as a mathematics educator, that is, as a teacher educator and as a classroom teacher in a secondary school. This is a personal account of the challenge of translating my beliefs about mathematics teaching and learning into everyday classroom practice. The presentation I use is based on the work of Rowland - the account is presented in the form of personal reflections on a story written about playing the two different roles of teacher educator and classroom teacher. I use the process of writing to try to make sense of my experiences and to explore the use of story as a research methodology. Although the story is intensely personal, there are identifiable themes that run through the narrative, which I suggest may resonate with the experience of other mathematics educators.
\end{abstract}

\section{Introduction}

This paper is a reflection on a story. The story is about two consecutive periods in my career in mathematics education - working as a teacher educator for a non-governmental organisation, followed by classroom teaching in a secondary school. The reflection is on my experience of change in moving from working with teachers to working as a teacher. This paper is, in fact, a story about a story for as Rowland (1997: 19) argues, "Reflecting is a way of storying". In this paper the reflections themselves constitute a story about my attempts to make sense of my experience.

\section{Background}

I spent the first four years of my career in mathematics education teaching in a secondary school. I was then given a three-year secondment to work as a project worker for a nongovernmental organisation, MathsLearn. ${ }^{1}$ The general aim of the project was to improve mathematics education through the development of learner and teacher materials, teacher education and research. As a project worker, I was expected to be involved in all three components of the project.

The work at MathsLearn was informed by what came to be called the "MathsLearn philosophy of teaching and learning", the features of which are as follows: a socio-constructivist view of mathematics and the learning of mathematics; researchbased materials development; learner-centredness; ${ }^{2}$

\footnotetext{
1 The name of the organisation has been changed.

2 "Learner-centred" in the MathsLearn sense means that the teaching and learning process recognises and builds on the
}

the promotion of both equity and excellence; and the belief that all learners can learn mathematics. National and international mathematics educators gave input into the development process and the work was trialed in selected project schools.

The MathsLearn project ended after three years and I returned to full-time classroom teaching, working with grade 10,11 and 12 learners in a secondary school. This school has an excellent record of academic achievement in the national examinations and is well known for its efforts to work with learners from varying educational backgrounds.

During my fourth year at this school, I presented a workshop at the Association for Mathematics Education of South Africa (AMESA) National Congress. In this workshop I shared ideas on the project work that my learners had been doing. A workshop participant posed the question, "I am interested in your move from being a teacher educator to a practising teacher at school level. Have you been able to apply what you were advising teachers to do?" "No, not at all," I initially replied. However, as I tried to explain my thoughts to the audience my answer changed. I ended my response: "Yes, everything I have done in the past four years has been influenced by my experience at MathsLearn."

This short exchange during the workshop, and my subsequent unease about my very different responses to the question, provided the spark for me to reflect on my experiences since leaving MathsLearn four years earlier.

existing knowledge of learners, and responds to their differen learning needs. 


\section{Motivation}

My reasons for writing this paper are threefold. Firstly, I feel that my experience of returning to classroom teaching after working in the field of teacher education is a rather unique one. The trend in the movement of educators appears to be in the opposite direction, from teacher to teacher educator. I feel that my reflections may shed some light on the complex relationship between teacher educator and classroom teacher.

Secondly, in writing this paper I have had an opportunity to explore the idea of writing a story as a method of research, as suggested by Rowland (1997). Lancy (1993: 169) notes that there is little tradition of personal accounts in educational research, but comments:

In general I see this area growing in importance as we find that humans use story or narrative to organise their understanding and memory of events. I also see that our best access to teachers' and students' understandings of the meaning of classroom experience may be through life narratives, rather than through structured classroom observations and interviews.

The view that meaning can be created through a narrative is based on a constructivist view of knowledge. Crotty (1998: 58) describes "constructivism" as "the meaning-making activity of the human brain". So, thirdly, from the constructivist perspective, the writing of this story could help me to make sense of my experiences of change.

\section{The structure of the paper}

The structure of this paper is based on Rowland's notion of reflections on a story (1997). The story about my experiences as a teacher educator and as a classroom teacher is written in the boxed sections of text. This narrative takes the form of descriptions of events and interactions I remember from a seven-year period. It also contains extracts from my writing as well as writing by my MathsLearn colleagues. These extracts have been selected to illustrate my thinking while playing the two roles, teacher educator and classroom teacher. My reflections on this story are given in plain text, in between the boxed text.

In presenting this paper for publication I have chosen to structure the narrative according to certain themes that emerged during the writing process. These themes, both personal and public, relate to wider issues in mathematics education. It should be noted that the decision to make use of this particular structure does not represent a conclusion in my reflections, but only one moment in the sense-making process. For me, the process of "storying" continues beyond the publication of this paper.

\section{The story}

\section{My career choices as a reflection of my values}

During the third year of MathsLearn the staff members are actively seeking work for the following year. I inform them of my intention to return to classroom teaching. A colleague asks, "So why go back to classroom teaching? Why not continue working as a teacher educator and use all that you have learnt in the past three years?"

The decision to return to classroom teaching in a secondary school was not taken lightly. My work as a MathsLearn project worker was interesting, challenging and exciting. I visited schools every week, working with teachers in their classrooms on implementing the MathsLearn approach to teaching and learning and trialing the MathsLearn materials. I had the luxury of being able to view the school system as an outsider and to reflect on the work of a classroom teacher. I was frequently reminded of the daily stresses of being a full-time teacher in a secondary school. Why, then, did I decide to return to this system?

The decision to return to teaching was a purposeful one on my part, and was certainly not a last resort when I could not find other work. Firstly, I definitely missed the challenge of teaching mathematics to teenagers, the daily interaction with these learners and the opportunity to get to know them as individuals. Secondly, there were times during my work as a teacher educator that I felt ill-equipped to advise the well-qualified and resourceful teachers with whom I was working. Who was I to advise teachers what to do, when I only had four years' teaching experience? I felt that, if I was to have credibility as a teacher educator in the long-term, I needed to gain more classroom experience.

Does this mean that I was not convinced of the practicality of the MathsLearn philosophy I had been advocating? I think not. I had seen the MathsLearn approach work in classrooms that were certainly more difficult than the situations I was likely to encounter in my new classroom. I wanted to try out what I had been working on for three years with my learners. I saw my classroom teaching as an opportunity to "develop", rather 


\section{Kate Bennie}

than to "test" the MathsLearn philosophy of teaching and learning.

Thirdly, on being offered a secondment to MathsLearn I was made aware that, as a practising teacher with only four years of experience, I was privileged to be given the opportunity to be part of this project. Throughout my three-year period of employment I was conscious of my position in this regard, as well as my duty to continue to make a contribution to mathematics education when the project ended. By returning to teaching, I was taking what I had learnt back to the classroom and to other mathematics educators.

My colleague at MathsLearn continues the challenge: "Well then, why not apply to work at a previously disadvantaged school? Why go to a private school?"

Prior to my secondment to MathsLearn I was employed at a secondary school. My job required that I not only teach mathematics, but that I also get involved in extra-mural activities. While I enjoyed these additional duties and could clearly see the value of this work, I gradually became frustrated by the time it was taking up. I felt that I did not have enough time to become the type of

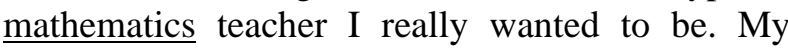
experiences while working at MathsLearn had confirmed to me that I had made a good choice of career. Now I wanted to find the environment in which I could do my work as a mathematics teacher to the best of my ability. My new appointment would provide the opportunity for me to focus on my teaching (without the pressure to get involved in extra-mural activities). Further, the opportunity to work with small classes of learners of varying mathematical ability would enable me to implement the MathsLearn ideas I so strongly believed in.

The choices I made about my career beyond MathsLearn were based on my values as an individual and as an educator: I value teenagers; I value classroom experience; I value finding personal fulfilment in my work; I want to be a good mathematics teacher; and I want to make a contribution to mathematics education in the country. By returning to teaching I was attempting to live in the direction of my values (McNiff, 2002: 13).

\section{Perspectives on equity}

While acknowledging the importance of the distribution of financial resources and the provision of a curriculum that caters for different genders, cultures, language groups, etc. in addressing the issue of "equity" in education, MathsLearn has developed particular views on the notions of "equity" and "diversity" and an accompanying teaching approach. This philosophy is based on the expectations we have of learners' abilities to do mathematics and is aimed at ensuring that all learners are successful in mathematics for longer than has been the case in the past. (Extract from a paper written by MathsLearn staff)

The term "equity" is used in a variety of ways in education, for example "equity as access", "equity as multiculturalism" or "equity as support". There is clearly a need to pay attention to these perspectives on equity in the context of South African schooling, for example through the provision of financial resources, infrastructure, appropriate curricula and support. Yet the context is a complex one. My experience of working with teachers at some of the MathsLearn project schools suggested that these so-called "previously disadvantaged" schools were staffed by the most talented and dedicated mathematics teachers I had yet encountered, and they performed their work under difficult circumstances. Working with these teachers forced me to interrogate my assumptions around the notions of "disadvantage" and "advantage" in relation to schooling, as well as my ideas on the role of teacher education in achieving equity in different schools.

The MathsLearn philosophy of equity is a broad notion that extends to all learners in all schools, whether classified as "advantaged" or "disadvantaged". The school at which I accepted a teaching post after the closure of MathsLearn offered me an opportunity to work with learners from a variety of academic backgrounds. Some of the learners were high achievers in mathematics, while others simply wanted a second chance at passing the subject. It was this feature of the school that was the deciding factor in taking the job as head of mathematics. In line with the MathsLearn philosophy of equity, here was my opportunity to help all learners take mathematics for longer.

Did it matter that not all the learners at the school were from so-called "previously disadvantaged" backgrounds? Working with learners drawn from a variety of schools and backgrounds, I was constantly reminded of the common difficulties all my learners had when learning mathematics. Of course some of the learners had to overcome great hurdles, for example, of learning mathematics in a second 
language, but many of the learners had a poor understanding of mathematical concepts such as fractions and functions. In my new job at the school it soon became very clear to me that there was a great deal to be done to help all the learners achieve their potential, no matter what their background.

Furthermore, a number of the learners who enrolled at the school had been told by their previous schools that they were either not capable of doing mathematics, or were not capable of doing the subject on the Higher Grade. These learners, many of whom were from "previously advantaged" schools were being filtered out of mathematics. While many of these assessments were clearly correct, some I believe were not accurate. During my time at the school I witnessed a number of learners who, given another chance and additional support, proved that they did have the potential to succeed. This did not mean that they passed grade 12 mathematics with distinction, but the fact that they had persevered and passed the subject was a great personal achievement for each one. And a most exciting and rewarding victory to witness.

Our view of "equity" is that all learners
can learn provided they are given
appropriate instruction and time. (Ex-
tract from a paper written by MathsLearn
staff)

John enters grade 10 at the school, having skipped grade 9 . He is determined to take mathematics, and we decide to give him a chance. Very soon I notice large gaps in his mathematical knowledge. For example, John cannot add and subtract integers mentally. When he tries these calculations on his calculator, he usually gets the wrong answer. After some questioning I notice that he cannot order integers on a number line. Following discussions with the school principal, I decide to work at a slightly slower pace with John. This leads to giving him different assessments to the rest of the class. None of the other learners seem to take much notice of this. John works hard during the year, and at the end of grade 10 he passes the same exam written by all grade 10 learners.

John continues with mathematics in grade 11, but by the middle of the year his absenteeism from the school is high.
When he does attend class he is aggressive and he repels my efforts to help him. He scrapes through the final exam, with the help of a private tutor. During his grade 12 year, John's high level of absenteeism continues. He shows little interest in his studies and he fails mathematics on the Standard Grade.

When John passed mathematics in grade $10 \mathrm{I}$ sensed that he might turn out to be one of the school's many success stories. Within two years this "success story" had failed the subject. I began to ask myself, "Can all children learn mathematics?"

In my first year at the school I have a large class of grade 11 students of mixed mathematical ability and mathematical background. They are typical teenagers boisterous and keen to test the tolerance level of their new mathematics teacher. Jason stands out as a particularly difficult member of this class. He seems intent on displaying an aggressive attitude towards both his teacher and his classmates.

Noticing the negative attitude of many of the learners in this class to the subject, I try to vary the tasks, often dipping into the wealth of resources I have brought with me from MathsLearn. On this particular day the learners are working on an investigation in algebra.

Predictably, Jason refuses to work with a partner as instructed and grudgingly begins the task. Gradually he makes progress and I am astounded by the mathematical skills I see being used before me: $\mathrm{He}$ is asking himself questions, investigating different possibilities and communicating his ideas with ease. I decide that this is one of the most exciting things I have seen in my classroom.

A year later, with a few months to go to the final grade 12 exam, Jason drops mathematics and takes another subject.

"Can all children learn mathematics?" Yes, I still firmly believe that this is so. In line with the MathsLearn philosophy of equity, John and Jason were given time and support, yet they did not succeed. My explanation is that there are other issues at play here. We cannot teach learners mathematics in a vacuum, removed from the everyday pressures of being a teenager. In both John and Jason's cases it appears that there were other factors, beyond the mathematics classroom, 


\section{Kate Bennie}

that prevented them from achieving their potential in mathematics.

\section{Using assessment to inform teaching and} learning

... assessment can be and should be a
communication process between the
teacher and the learners, a process that
supports teaching and learning. It is a
tool that fosters equity by providing the
teacher with the necessary analysis of the
learner's needs. The needs, if not
fulfilled, will in the long run filter them
out of mathematics. If we want to give
learners a fair chance to succeed in
mathematics in the long run, and not only
in the short term, we have to find ways to
support them in the construction of some
key mathematical notions.(Extract from a
paper written by MathsLearn staff)

Using diagnostic assessment I was able to identify gaps in John's understanding of number. I had the support of the school principal to use different assessments with different learners. Diagnostic assessment and the use of assessment to inform teaching are integral to the MathsLearn philosophy, but there were many times in my four years in the classroom that I asked myself, "Is my approach learner-centred in the MathsLearn sense? Am I really working from what the learners know?" I often felt that I was not spending enough time doing diagnostic assessments and profiles of learners' understandings to help me plan my teaching. There just seemed to be no time. I have a possible explanation for my feeling of dissatisfaction with my performance. Thinking back I was, in fact, using diagnostic assessment, whether this was in the form of specific diagnostic tests at the beginning of a section, information I gathered from formative assessments, or from my observations of the learners and my interaction with them. Perhaps trying to assess my learners' understanding had become so much part of my daily teaching that I was unaware of actually doing it. Perhaps the fact that I kept questioning my practice and feeling dissatisfied with my performance, means that I was constantly aware of the need to be learner-centred.

\section{"Covering" the curriculum}

There is another possible reason for my dissatisfaction with my ability to implement the MathsLearn philosophy. Although I think I had an understanding of the needs of my learners, I often felt powerless under the time-constraints to respond to their needs. Although some of my learners entered the school in grade 10, a large proportion only joined the school in their grade 11 or 12 year. I continue to ask myself, "Given the need to prepare learners for the current matric exam, is it realistic and even possible to fill the gaps in learners' conceptual understanding in a short time?"

Sam had completed twelve years of schooling and had passed Standard Grade mathematics in grade 12 . She enrolls at the school to repeat her grade 12 year in the hope of improving on her performance. One of her aims is to pass mathematics on the Higher Grade. She is a remarkably determined and diligent learner. We meet once a week after school hours to work on the subject. During one of these sessions I notice that she has no concept of a number line and cannot order numbers on a number line.

Carter and Richards (1999: 73) refer to "the universal issue/dilemma of time" and "the teachers' belief that if they do not spend enough time "covering" the "curriculum" they will be damaging their students." "Covering" the curriculum certainly seems a safe route for the teacher: if she can place a "tick" in the correct space next to each mathematics topic in the work scheme, then it appears that she has done her work (and hence not "damaged" the learners). But I would argue that if teachers focus on completing the syllabus at the expense of conceptual understanding they may, in fact, be "damaging" their learners. Sam had studied school mathematics for twelve years, yet she had no concept of the number line. She had passed Standard Grade mathematics in grade 12, but what does this result say about her understanding of the subject?

The final grade 12 examinations are coming closer and closer. I lie awake at night, "Will I finish the syllabus? Will I finish the syllabus? Will I finish the syllabus?" runs through my mind, over and over.

Although I had strong feelings about teaching for understanding, I was working within a system at the school that required me to complete the grade 12 syllabus each year, and to make a very good job of it, too. Fortunately I was given a certain amount of flexibility in grades 10 and 11 to work on learners' grounding in mathematics. But each year, I was faced with new learners who only entered the school in grade 12, many of whom had large gaps 
in their mathematical understanding. What happened to my dreams of implementing the MathsLearn approach to teaching and learning?

Despite my attempts to be learner-centred in the MathsLearn sense, there were times that I resorted to "chalk-and-talk" in grade 12. I am not proud of this, but the only redeeming feature I can find in this experience is that this approach was accompanied by a constant sense of unease about what I was doing. I could never accept this approach as "The way mathematics teaching is". This was definitely not the type of mathematics teacher I wished to be.

\section{Innovation in the classroom}

Looking back I realise that I adopted certain strategies to cope with my frustration at having to "cover the syllabus" and at the same time keep the MathsLearn vision alive. For example, I worked at a slightly slower pace than some of my colleagues, as I tried to build in some remediation of the problems I diagnosed along the way. So after a test, I did not proceed on to the next topic immediately, but dedicated a small amount of time to trying to work with learners on their difficulties. This was usually followed by a re-assessment. This meant that I did not have three weeks for revision before exams, as many of my colleagues had, but my explanation to them (and to my learners who expected this revision time), was that I had been revising all along. My experience at MathsLearn had given me reservations about teaching a topic relatively quickly without remediating along the way. To me this was creating a need for lengthy revision before examinations. I was concerned that, by working too fast, I would be losing some learners along the way. I also had a sense that some learners tended to rely on revision as part of the teaching process: "Why learn it now if there will be another chance later?"

When I planned my teaching of a new topic, I tried wherever possible to revisit a topic studied earlier. So when teaching quadratic inequalities, I built in opportunities to revisit the theory of quadratics and solving quadratic and cubic equations. In my view, my learners were constantly being required to revisit their earlier learning. Some learners did find this approach challenging. To them it was "not how maths is taught". However, my experience of working with teachers and their classes at MathsLearn had taught me that an innovation will only succeed if one perseveres. So rather than giving up on the approach, I tried to address their concerns and continued to work on the innovation.

When working under pressure to
complete the rather overloaded grade 12
curriculum, I struggle to find time to help
learners make the links between different
topics they are studying. This skill of
integrating knowledge across topics is
one that I would like my Higher Grade
learners to develop, not only because it
will assist them in their final grade 12
examinations, but also because it will be
of great benefit in their further studies. In
order to tackle this problem I have
developed a project that challenges
learners to reflect on all the mathematics
they have studied in their 12-year school
careers. This project-work is one
component of learners' CASS portfolios.
(Extract from "Looking for links in
mathematical topics: Project work for
grade 12", a workshop presented at the
AMESA Congress, 2003)

The project on links in mathematics became one of the highlights of my grade 12 teaching each year (it was, in fact, an idea I got from a teacher at a MathsLearn project school). It gave me an opportunity to digress from the daily routine of "covering" the curriculum and to give learners a chance to apply their learning in different ways. It was also an opportunity to do some action research of my own, as I used my experiences of using the project to adapt the material each year.

\section{Promoting a community of mathematics educators}

In general MathsLearn staff have
noticed a change in the focus of all six
teachers at the school. Discussions
during window sessions ${ }^{3}$ now involve
teachers' descriptions of the
mathematical strategies used by their
learners rather than discussion of
administrative details. (Extract from a
paper written by MathsLearn staff)

When I began my new teaching post at the school I had visions of sharing what I had learnt at MathsLearn with my new colleagues. I thought I could continue with my work as a teacher educator. Not only did I firmly believe in the MathsLearn philosophy, but I had also come from a very stimulating environment in which I was able

\footnotetext{
3 A "window session" is the term used by MathsLearn staff for a scheduled period during the school day in which all mathematics teachers are freed from their teaching duties to meet as a group to discuss and reflect on their work.
} 


\section{Kate Bennie}

to talk about our work with the project school teachers and my fellow project workers. For three years I had been challenged to reflect on what I was doing. I certainly hoped that this would continue.

I am watching Sue at work on a mathematics problem. I notice that she makes an error when she manipulates a fraction. I am fascinated by the thinking behind her approach, which emerges as I try to assist her. At the end of the lesson my first thought is, "I must share this experience with my colleagues". I join the other teachers in the staff room at lunchtime. I listen to the conversation, but somehow I don't find an opportunity to share this classroom event.

As head of mathematics at the school I organised for all the mathematics teachers to meet once a week or once a fortnight. I hoped that we would be able to talk about what was going on in our classrooms. To encourage teachers to focus on the mathematics happening in their classrooms, I tried giving them some preparation for each meeting, for example, something specific to look out for in their classes. But the meetings seldom developed as I intended. They either became discussions of administrative issues or never took place at all.

Can I explain this? Firstly, it seems that teaching has become a matter of "survival" for many teachers. Focusing on strategies used by learners in the classroom is often not the first priority. Ironically, my experiences at MathsLearn meant that focusing on the mathematics going on in my classroom was probably the most exciting part of my work. This became my way of "surviving" the other pressures that went with my role as a secondary school teacher. I so desperately wanted to share what I observed with my colleagues.

Secondly, many of my colleagues at the school were highly experienced and good teachers. Over the years they had refined their methods, and they saw no need to change their teaching practice. Interestingly, as the implementation of the new curriculum in grades 10 to 12 approached, some of my colleagues became more interested in my experiences at MathsLearn. It was only after three years at the school that I had an opportunity to workshop these ideas with the staff.

How much influence did I have on the school's teachers in the four-year period? The use of the grade 12 project described earlier provided an exciting opportunity for mentoring of my colleagues who used this project in their classrooms. One of the teachers subsequently copresented an AMESA workshop on our use of the projects. However, in general I have a sense of making little progress in conveying the MathsLearn philosophy to my colleagues. Most of my opportunities to talk about the work of MathsLearn were in one-to-one discussions with a few of my colleagues when we discussed our classroom practice. Perhaps I planted a spark in the minds of these colleagues. However, I have no way of measuring the impact of my ideas on these teachers.

There were many occasions during my time at the school when I missed what might be called the "MathsLearn community", that is, the opportunity to talk about and reflect on issues in education and in mathematics education in particular. But my involvement in AMESA helped me to cope with this frustration. When MathsLearn closed I was determined to continue my involvement in AMESA. I think I saw this involvement as a way of giving something back to mathematics education after having benefited so much from my three years at MathsLearn. But on reflection I realise that it was not just me giving something back, but me getting something from AMESA. For here was a community in which the MathsLearn ethos could be kept alive.

\section{Some remarks as the "storying" continues}

Kate, do you know what your problem is? You do not reflect on what you do. (Extract from a discussion at MathsLearn)

My three years as a project worker at MathsLearn were a challenge, both professionally and personally. When I began working at MathsLearn I was thrown completely out of my comfort zone, and in that three-year period I never seemed to regain it. One challenge just led to another and I was on a constant learning curve. And what did I learn? I believe that, most importantly, my MathsLearn experience taught me to reflect on myself and on my work. This "story about a story" is an illustration of how I have learned to reflect on my experiences and my values.

Does this "story about a story" have any value? Can "storying" be regarded as research? From the constructivist perspective, the process of writing has certainly helped me to organise my understanding of my experiences as a teacher educator and classroom teacher. For if I was once again asked the question "I am interested in your move from being a teacher educator to a practising teacher at school level. Have you been able to 
apply what you were advising teachers to do?" I would definitely reply "Yes, everything I have done in the past four years has been influenced by my experience at MathsLearn".

But this is just one story about one story. In writing the story about my experiences over a seven-year period, I have used either my most vivid memories or what I regarded as important at the time of writing. In preparing this paper for publication I have used themes to organise the story, for example, my values as an educator, perspectives on equity, and promoting a community of mathematics educators. However, each time I read my reflections on this story, I construct another, slightly different story. This process will continue. Each reader of this paper will read a different story. One reader may identify with the themes used to structure the paper. For another reader, this narrative may be interpreted as a story about how teachers and teacher educators adopt different discourses. For another reader, this may be a story of how a teacher may retain certain core beliefs, but act differently in different settings. For yet another reader, this may be a story about...

\section{References}

Bennie, K., (2003). Looking for links in mathematical topics: Project work for grade 12 . In S. Jaffer \& L. Burgess (Eds.), Proceedings of the $9^{\text {th }}$ Annual Congress of the Association for Mathematics Education of South Africa, 2 (pp. 21-25). Cape Town, South Africa.
Bennie, K., Olivier, A. \& Linchevski, L. (1999). Everyone can learn mathematics: Addressing the fundamental assumptions and goals of Curriculum 2005. In Proceedings of the $5^{\text {th }}$ Annual Congress of the Association for Mathematics Education of South Africa, 2 (pp.10-24). Port Elizabeth, South Africa.

Carter, R. \& Richards, J. (1999). Dilemmas of constructivist mathematics teaching: Instances from classroom practice. In B. Jaworski, T. Wood \& A. Dawson (Eds.), Mathematics teacher education: Critical international perspectives (pp.69-77). London: Falmer Press.

Crotty, M., (1998). The foundations of social research. St Leornards: Allen and Unwin.

Lancy, D.F., (1993). Qualitative research in education: An introduction to the major traditions. London: Longman.

Linchevski, L., Liebenberg, R., Sasman, M. \& Olivier, A. (1998). Assessment in support of planning teaching to improve learning. In Proceedings of the $4^{\text {th }}$ Annual Congress of the Association for Mathematics Education of South Africa (pp.47-52). Pietersburg, South Africa.

McNiff, J. (2002). Action research for professional development: Concise advice for new action researchers [Booklet]. Retrieved July 19, 2005, from http://www.jeanmcniff.com

Rowland, S. (1997). Reflections on a story, Academic Development, 3(2), 19-36.

\author{
"Learning \\ is finding out \\ what you already know. \\ Doing is demonstrating that \\ you know it. \\ Teaching is reminding others \\ that they know just as well as you. \\ You are all learners, \\ doers, teachers."
}

Richard Bach 